\title{
Caracterização Ultra-Sônica Tecidual Miocárdica
}

\author{
A ntonio Pazin-Filho, André Schmidt, O swaldo C. Almeida-Filho, José A. Marin-N eto, \\ Benedito C. Maciel
}

Ribeirão Preto, SP

Ao longo das últimas décadas, os métodos ultrasonográficos de investigação cardiovascular receberam avanços tecnológicos, contribuindo decisivamente para o aprimoramento diagnóstico e prognóstico de doenças, que apresentam envolvimento cardíaco. Não obstante ter a ecocardiografia se consolidado como método de ampla utilização clínica, em face do amplo conjunto de informações morfológicas e funcionais que essa técnica pode proporcionar, os avanços relativos à sua capacidade de permitir inferências relativas à constituição anatômica de estruturas cardíacas eram, até recentemente, bastante limitados.

Desde o início do desenvolvimento da ecocardiografia, era possível documentar que algumas estruturas eram mais refringentes do que outras, o que, em muitas ocasiões, podia ser correlacionado com a constituição da estrutura observada. Assim, por exemplo, em pacientes com infarto agudo do miocárdio prévio ou em portadores de miocardiopatia, pode-se distinguir áreas do miocárdio mais refringentes e que se correlacionam com a presença de fibrose ao estudo anatomopatológico ${ }^{1}$. Do mesmo modo, valvas calcificadas apresentam-se mais refringentes ${ }^{2}$, assim como o miocárdio de portadores de amiolóidose ${ }^{3}$. No entanto, esta análise revela-se simplista, subjetiva e grosseira, em muito devido ao fato de que outros fatores estão envolvidos na gênese do grau de refringência observado. Dentre estes vários fatores, destacam-se os diversos métodos de processamento do sinal de ultra-som utilizados pelos fabricantes e os ajustes do equipamento, dependentes do operador.

No entanto, estas observações iniciais apontavam a perspectiva da ecocardiografia tornar-se um método menos subjetivo de avaliação e com potencial para: 1) identificar e localizar mudanças precoces no tecido antes que ocorram alterações grosseiras na estrutura anatômica e na função 2) discernir mecanismos de injúria (diferenciação entre mio-

Faculdade de Medicina de Ribeirão Preto, USP

Correspondência: Benedito Carlos Maciel - Faculdade de Medicina de Ribeirão Preto-Cardiologia - 14048-900 - Ribeirão Preto, SP - e-mail: bcmaciel@fmrp.usp.br Recebido para publicação em 29/10/02

Aceito em 14/1/03 cardite, isquemia e trauma, como causa de mobilidade parietal segmentar anormal); 3) quantificar a extensão da mudança ou envolvimento; e 4) diferenciar tecido normal, embora não funcionante de tecido lesado ou necrótico ${ }^{4}$.

A perspectiva concreta de utilização da ecocardiografia na análise das características anatômicas ultra-estruturais do músculo cardíaco abriu-se durante a última década, com a técnica da caracterização tecidual, que avalia, quantitativamente, as alterações nas ondas de ultra-som durante sua interação física com o tecido miocárdico, permitindo estabelecer correlações com as propriedades físicas das estruturas do tecido miocárdico ${ }^{4}$.

Quando o feixe de ultra-som, emitido pelo transdutor, incide sobre os tecidos, basicamente dois tipos de sinais refletidos retornam ao transdutor. Eles são diretamente dependentes da relação entre a dimensão da superfície atingida pelo feixe de ultra-som e o comprimento de onda desse feixe $^{5}$ (fig. 1). Assim, existe um primeiro conjunto de sinais decorrentes do fenômeno de reflexão especular do ultrasom, incidindo sobre superfícies que apresentam dimensão muito maior que o comprimento de onda do ultra-som; mas também existe um outro, decorrente do fenômeno de dispersão (em inglês, scatter), ocorrido quando a dimensão da superfície sobre a qual incide o feixe de ultra-som é muito menor que o seu comprimento de onda. Ao contrário do fenômeno de reflexão, que se dá preferencialmente em uma direção, o fenômeno de dispersão é multidirecional e apenas uma parte pequena do ultra-som dispersado pode ser captada pelo transdutor (conhecido como backscatter). O fenômeno de dispersão é o responsável pela produção dos sinais que são processados para análise de velocidade e direção de fluxo sanguíneo (técnica de Doppler), ao mesmo tempo que depende da heterogeneidade regional das propriedades físicas do tecido, especialmente de densidade $\mathrm{e}$ compressibilidade, quando interage com o ultra-som, além da extensão e distribuição dessa heterogeneidade ${ }^{5}$.

Para a obtenção das imagens ecocardiográficas bidimensionais convencionais, são utilizados os sinais oriundos da reflexão especular, que permitem imagens de melhor resolução espacial, enquanto os sinais provenientes do 


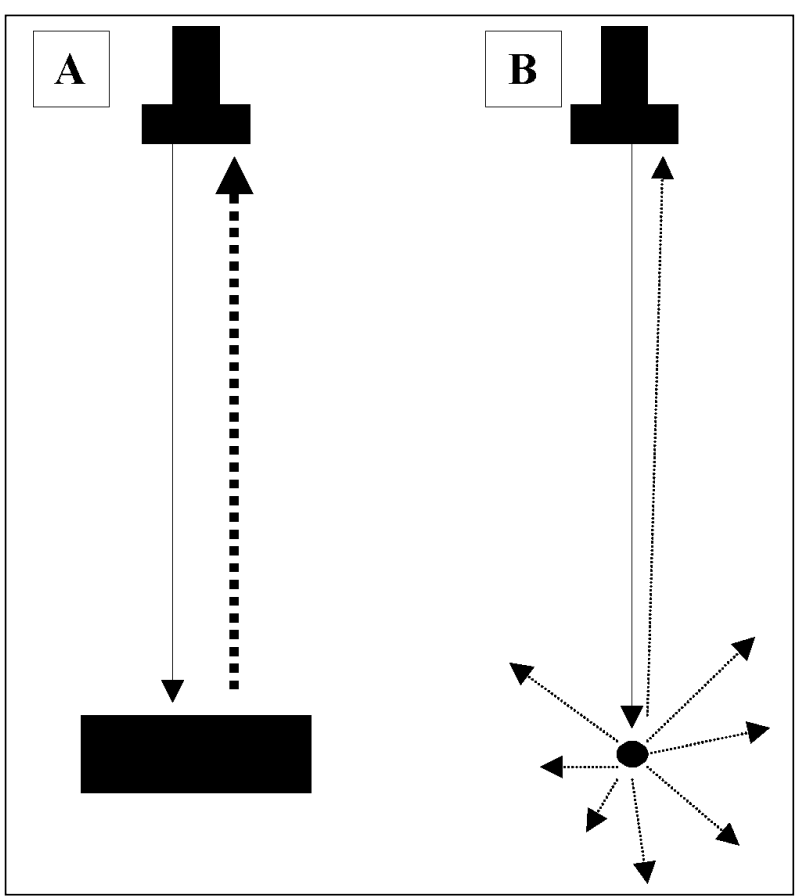

Fig. 1 - Exemplo dos dois tipos de sinais comumente utilizados em Doppler ecocardiografia: A) exemplo do fenômeno de reflexão, ocorrido quando o feixe de ultra-som incide sobre uma superfície maior do que o comprimento de onda do feixe, e é normalmente utilizado para a composição das imagens bidimensionais convencionais; B) exemplo do fenômeno de dispersão (scatter), ocorrido quando o feixe de ultra-som incide sobre uma superfície menor do que o comprimento de onda do feixe, utilizado para a composição do sinal de Doppler, mas o sinal oriundo do tecido é normalmente filtrado (eliminado pelo imageamento convencional) pelo aparelho. Este tipo de sinal é a base da caracterização tecidual ultra-sônica.

processo de dispersão são filtrados pelo equipamento. Após serem isolados, os sinais da reflexão especular são submetidos a diversos níveis de processamento, de modo a proporcionar um aprimoramento adicional na resolução espacial e temporal da imagem.

A técnica de caracterização tecidual ultra-sônica desenvolveu-se a partir da análise dos sinais originários do fenômeno de dispersão ultra-sônica, que, potencialmente, podem correlacionar-se com a estrutura do tecido sobre o qual o ultra-som incide, o que tem sido estudado na literatura através de métodos qualitativos e quantitativos. Dentre os métodos quantitativos, onde se tem fixado a maior parte da pesquisa realizada neste campo até o momento, dois tipos básicos têm sido descritos: a estimação paramétrica e a classificação ${ }^{4}$. Na estimação paramétrica, uma propriedade específica da onda sonora (e.g. sua velocidade, fase, atenuação, ou a magnitude com a qual ela é refletida) é mensurada e relacionada diretamente com alguma propriedade fundamental do tecido, como, por exemplo, o conteúdo de fluido ou colágeno. Nessa situação, a caracterização tecidual ultra-sônica é tratada como um problema de análise de sinal. Já a classificação fundamenta-se em um padrão de reconhecimento e em técnicas de processamento de sinal (similares àquelas utilizadas na análise de voz ou de impressões digitais) para definir as características estatísticas e espaciais principais de ondas sonoras individuais e, com base nessa análise, permitir a identificação de um tecido. Neste caso a caracte- rização tecidual ultra-sônica é considerada como um problema estatístico e matemático.

O método de estimação paramétrica tem sido amplamente investigado e foi recentemente disponibilizado comercialmente em equipamentos de ultra-som para a análise de um de seus aspectos, o integrated backscatter. Esse fenômeno de dispersão retrógrada do ultra-som, em geral, tende a ser um fenômeno omnidirecional, não podendo ser captado pelo transdutor em sua totalidade, mas apenas parcialmente, implicando que o backscatter, a porção desta energia captada pelo transdutor, constitui apenas uma parcela pequena, mas representativa da energia total dispersada. O backscatter depende de uma série de propriedades físicas do ultra-som, incluindo sua freqüência, bem como da regulagem do equipamento. Porém, também depende de várias propriedades físicas fundamentais do tecido, como a elasticidade local, densidade e geometria da fibra (forma, tamanho, concentração e orientação $)^{6}$. Esses elementos permitiram que se estabelecesse a hipótese de que a análise dessa energia refletida pudesse caracterizar uma "impressão digital" do tecido, que dependeria de seus componentes intrínsecos e fosse alterada por estados patológicos, como por exemplo, as alterações determinadas por miocardites ou pelo infarto agudo do miocárdio.

\section{O integrated backscatter}

O integrated backscatter, um dos métodos de estudo da caracterização tecidual, é classicamente definido como a média da energia presente no espectro de freqüência do feixe de ultra-som refletido ${ }^{7}$. Originalmente explorado no domínio da freqüência, seu cálculo inicia-se pela transformação de Fourier do sinal de ultra-som refletido do miocárdio para obtenção de um espectro de freqüências. Para obter-se uma informação espectral completa, é necessária a compensação devido às características do transdutor, obtidas pela correção por um espectro de referência originário de um refletor padrão. Finalmente, a média das freqüências do espectro é estabelecida para o cálculo do integrated backscatter.

Conforme já salientado, no sistema de ecocardiografia convencional, o sinal recebido pelo transdutor é filtrado e somente os ecos especulares que retornam de superfícies mais amplas são usados para criar uma imagem com melhor resolução espacial. Para que seja possível o estudo do sinal de caracterização tecidual ultra-sônica, o sinal deve sofrer um processamento alternativo ${ }^{7,8}$ (fig. 2), o que implica em perda de definição da imagem convencional (fig. 3).

Diversas variáveis podem influenciar na determinação do integrated backscatter, podendo ser agrupadas em três categorias básicas: 1) características do sistema de ultrasom - o conjunto de todas as variáveis dependentes do sistema de ultra-som empregado, incluindo fatores determinados pelo operador (time-gain compensation, freqüência, ganho lateral, ganho total, pré-processamento, profundidade da imagem, foco), fatores determinados pelo fabricante (compensação ganho-profundidade automática, padrão do 


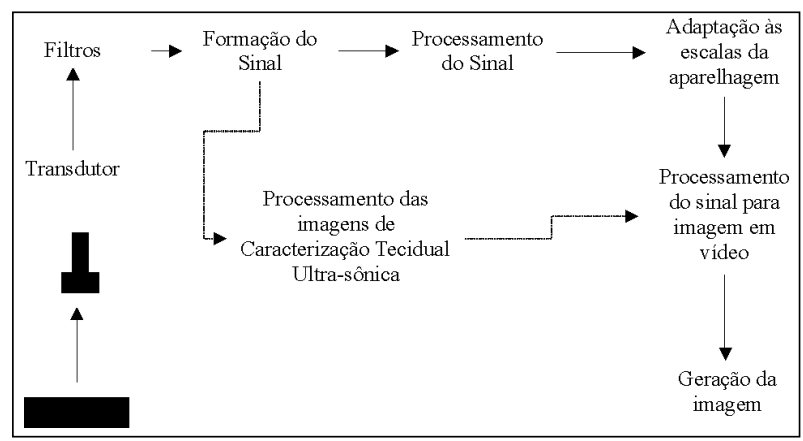

Fig. 2 - Esquema geral da seqüência de processamento do sinal de ultra-som nos equipamentos disponíveis comercialmente. Setas pontilhadas demonstrando o processamento alternativo que o sinal sofre para gerar as imagens de caracterização tecidual ultra-sônica.

feixe de ultra-som, função de emissão e recepção do sistema) e fatores do acoplamento do sistema de ultra-som ao indivíduo estudado; 2) atenuação do feixe de ultra-som, em última análise dependente da distância do transdutor ao ponto investigado; e 3) coeficiente de backscatter, inerente ao tecido interrogado 9 . A multiplicidade de fatores envolvidos na determinação do integrated backscatter torna a comparação dos valores obtidos em diferentes equipamentos, que utilizam ajustes diversos, praticamente impossíveis.

Várias técnicas foram empregadas na literatura na tentativa de se realizar a padronização destas variáveis, com o intuito de isolar o fator dependente do tecido coeficiente de backscatter). Podem ser agrupadas em três intervenções básicas: 1) manutenção dos ajustes do aparelho constante entre indivíduos - que, apesar de coerente do ponto de vista de investigação científica, torna-se inviável do ponto de vista operacional, pois limitaria a obtenção de imagens com qualidade adequada, em grande parte dos indivíduos estudados; 2) utilização de modelos matemáticos de correção, baseados em complexas pressuposições do efeito do ultrasom sobre os tecidos; e 3) correção dos valores obtidos, utilizando-se um referencial sujeito aos mesmos ajustes de aparelhagem da imagem estudada ${ }^{10}$.

A correção através de um referencial tem sido considerada como o método ideal para permitir a comparação entre indivíduos. As técnicas são diversas e apresentam variações: a) tipo de correção utilizada - alguns estudos subtraem o valor obtido no tecido sob investigação do observado no referencial ${ }^{11}$, enquanto outros utilizam a divisão entre as duas medidas ${ }^{12-15}$ b) tipo de referencial empregado alguns estudos utilizaram o valor de integrated backscatter documentado no interior da cavidade ventricular ${ }^{16}$ e outros o seu valor obtido no pericárdio ${ }^{11}$, embora a utilização de referencial com valores conhecidos de integrated backscatter, também ocorra como phantoms de borracha ${ }^{10}$. No que diz respeito ao tipo de material utilizado como referencial, cabe ressaltar que a medida do integrated backscatter no interior da cavidade ventricular e do pericárdio, não leva em consideração a profundidade da região estudada. Assim, um segmento septal pode estar distante cerca de $5 \mathrm{~cm}$ da região de pericárdio utilizada para se obter o referencial (geralmente a região localizada próxima à parede posterior do ventrículo esquerdo, mais facilmente observada por ser mais refringente). Considerando-se que a profundidade é um dos determinantes da atenuação do feixe de ultra-som, esta limitação da técnica pode implicar em dificuldade de comparação dos dados obtidos. A utilização de phantoms para a definição do valor de integrated backscatter de referência mostra-se bastante atraente, uma vez que permite estabelecer comparação inter-indivíduos, levando em con-
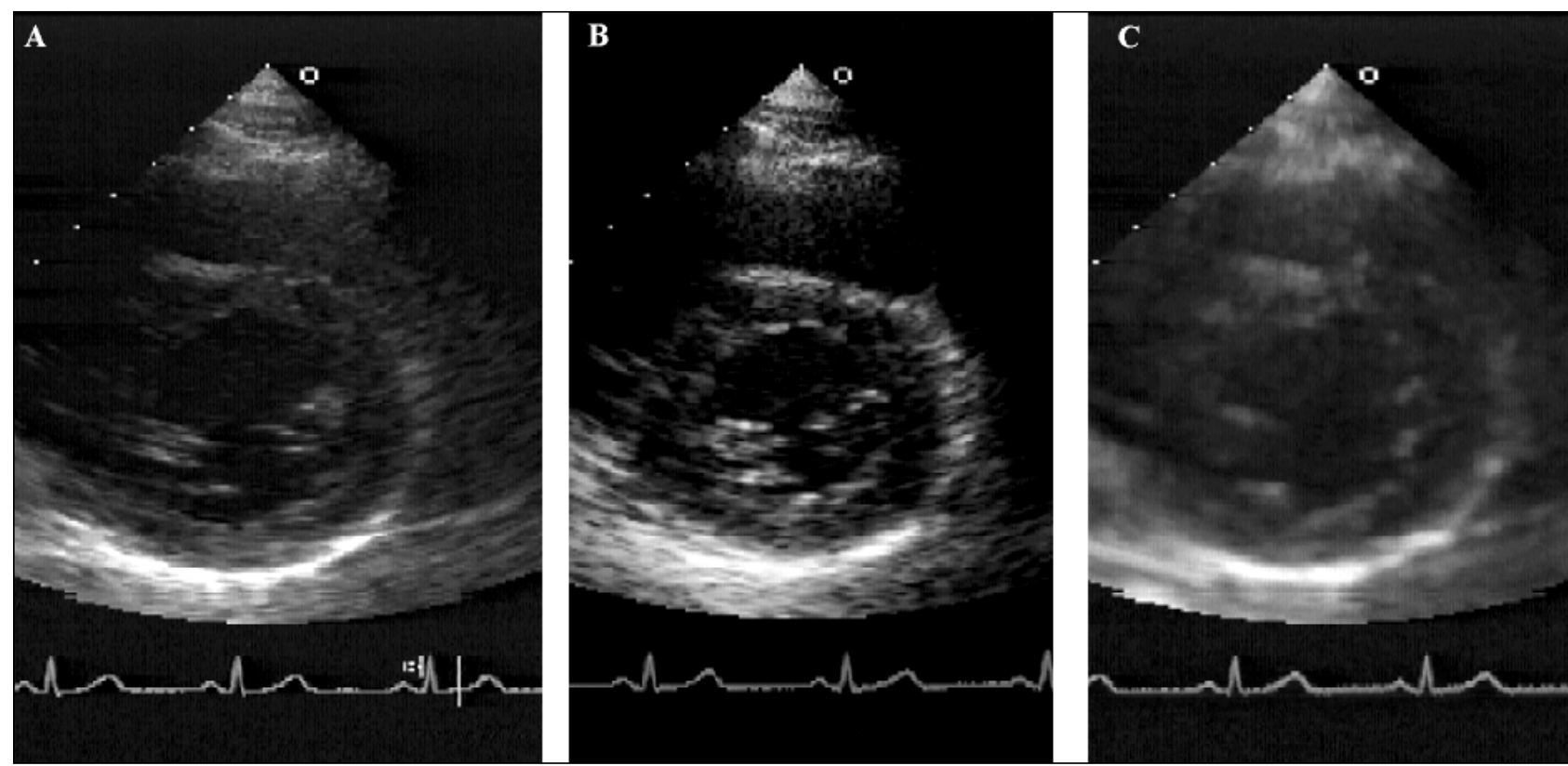

Fig. 3 -Exemplo da diferente resolução obtida com as diversas técnicas de processamento de imagem comercialmente disponíveis: A) exemplo de uma imagem fundamental no corte paraesternal em eixo curto ao nível dos músculos papilares; B) o mesmo corte obtido com o recurso de segunda harmônica; C) o mesmo corte, agora com o recurso da caracterização tecidual ultra-sônica. Observe a perda da definição da imagem em C. 
sideração, em cada medida, a profundidade da amostra. Essa técnica permite, desde que mantidos inalterados os controles do equipamento, estimar o coeficiente de backscatter. Um exemplo da utilização de phantoms de borracha para correção do integrated backscatter encontra-se na figura 4.

A caracterização dos componentes do miocárdio responsáveis pelo coeficiente de backscatter ainda não foi estabelecida. Por se constituir em uma característica do tecido, pode estar relacionado aos seus componentes macromoleculares básicos ${ }^{17}$. Basicamente, quatro componentes poderiam estar implicados na sua gênese: água, proteína, colágeno e gordura. Assim, o edema que as alterações agudas do infarto agudo do miocárdio provocam no tecido miocárdico poderia explicar o aumento do integrated backscatter observado nessa condição clínica, já que o conteúdo de água têm sido correlacionado com diminuição do coeficiente de atenuação e aumento da velocidade do ultra-som ${ }^{17}$. Observações similares quanto à influência do conteúdo de água tissular sobre o coeficiente de backscatter foram feitas para outros modelos patológicos ${ }^{18}$. Do mesmo modo, o aumento do conteúdo de colágeno presente no processo de fibrose comum a vários processos patológicos cardiovasculares poderia implicar em maior intensidade do integrated backscatter $^{19,20}$. Isto têm sido observado em vários estudos $^{18,21,22}$. No que concerne à contribuição do conteúdo protéico e lipídico na determinação do coeficiente de backscatter, os estudos são menos claros ${ }^{21}$.

A importância do colágeno, como principal constituinte do processo fibrótico, instaurada em diversas doenças com envolvimento cardiovascular, colocou em questão a possibilidade de se utilizar o integrated backscatter para se detectar precocemente estas alterações. Esperava-se que o maior acúmulo de colágeno inerente ao processo de fibrose alterasse o coeficiente de backscatter do tecido e, se a técnica fosse sensível o suficiente, este aspecto poderia preceder alterações de função ou forma. Essa associação foi demonstrada em modelos que envolveram diversas doenças, como diabetes mellitus ${ }^{12}$, hipertrofia ventricular e miocardiopatia hipertrófica ${ }^{13-16,23}$, pacientes com talassemia maior em regime de transfusões múltiplas ${ }^{24}$ e em alterações cardíacas decorrentes do uso de quimioterápicos ${ }^{25}$. Em nosso laboratório, documentamos valores de integrated backscatter

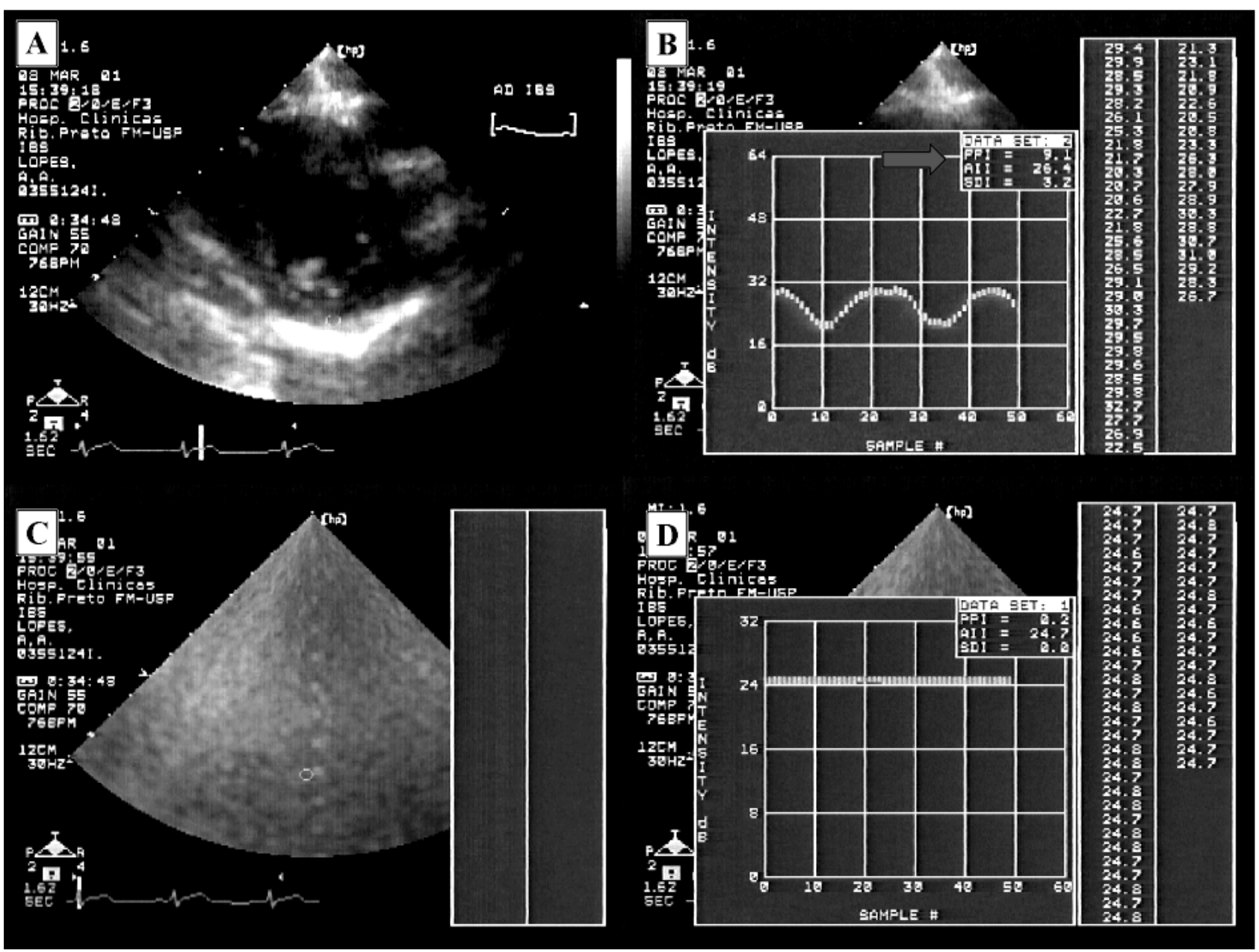

Fig. 4-A) imagem de caracterização tecidual ultra-sônica de um corte do ventrículo esquerdo na projeção de eixo curto ao nível da valva mitral com a região de interesse (RI) colocada no segmento inferior basal; B) exemplo da curva produzida pela investigação do segmento inferior basal mostrado em A, onde se observa nas ordenadas o valor do integrated backscatter e nas abscissas o número do quadro de 1 a 60 correspondente; no canto superior direito da curva (seta vermelha) os valores resultantes de AII, PPI e SDI; C) exemplo da região de interesse (RI) colocada à mesma profundidade e na mesma posição daquela mostrada em A na imagem obtida a partir do "phantom" de borracha, obtida com os mesmos ajustes do aparelho utilizados em A; D) exemplo dos parâmetros de integrated backscatter obtidos no "phantom". A disposição é a mesma daquela observada em B. 
significativamente maiores em cardiopatas chagásicos que em portadores das formas indeterminada e digestiva, ou em indivíduos normais. Do mesmo modo, esta técnica mostrouse capaz de identificar precocemente o envolvimento cardíaco na doença de Chagas, em segmentos que apresentavam a mobilidade parietal preservada (fig. 5).

Outras evidências indicam que, além da concentração, a organização estrutural e tridimensional ${ }^{19}$ dos componentes macromoleculares desempenharia papel na determinação do coeficiente de backscatter, considerando-se, primordialmente o esqueleto de colágeno tridimensional que circunda as fibras miocárdicas, como o principal fator contribuinte. Esta hipótese encontra alicerce nas evidências de que a intensidade do integrated backscatter é dependente da orientação do feixe de ultra-som em relação à orientação das fibras do tecido estudado ${ }^{20,26}$.

Outra característica do integrated backscatter é a variação de sua intensidade ao longo do ciclo cardíaco. Estudos iniciais demonstraram que, ao verificar o seu comportamento nos segmentos septais anteriores e na parede posterior nas projeções paraesternais, observava-se um padrão característico, definido pela diminuição da intensidade do integrated backscatter com a contração cardíaca ${ }^{27}$. Essa característica pode refletir, portanto, a função contrátil do tecido, ao contrário do valor absoluto do integrated backscatter, que estaria correlacionado em maior grau aos seus componentes estruturais. Favoráveis a este argumento, são as evidências de que medicações que alteram a contratilidade ventricular influenciam a magnitude da variação do integrated backscatter, observando-se aumento com o uso de inotrópicos positivos (dobutamina) e diminuição com inotrópicos negativos (beta-bloqueadores) ${ }^{28,29}$, embora outras variáveis que influenciam a função ventricular, como pré e pós-carga e freqüência cardíaca, não tenham demonstrado efeito significativo sobre a sua variação cíclica ${ }^{29}$

Estudos envolvendo isquemia aguda do tecido miocárdico demonstraram que a variação cíclica do integrated backscatter é abolida durante a isquemia ${ }^{30}$, ocorrendo recuperação gradativa, com velocidade variável, na dependência do tempo de isquemia sofrido pelo tecido. De particular interesse é a observação de que a recuperação da variação cíclica é anterior ao restabelecimento da função contrátil do miocárdio, levantando a possibilidade de se utilizar esta característica como marcador de miocárdio atordoado ${ }^{31}$. Em modelos de isquemia crônica, uma maior amplitude de variação cíclica do integratted backscatter está correlacionada a uma resposta positiva frente ao estímulo com dobutamina, implicando em potencial para identificar segmentos viáveis $^{32,33}$.

Estudos envolvendo miocardiopatia dilatada ${ }^{22,34} \mathrm{e}$ hipertrófica ${ }^{35}$ demonstraram redução da amplitude da variação cíclica do integrated backscatter em comparação aos controles normais. Frente ao estímulo com dobutamina, à amplitude da variação cíclica do integrated backscatter não sofreu alteração em portadores de miocardiopatia dilatada, enquanto apresentou aumento em voluntários normais $^{36}$.

Outros fatores podem influenciar o comportamento da variação cíclica do integrated backscatter além daqueles inerentes ao estado contrátil. O tecido miocárdico apresenta diferentes características ultra-sônicas na dependência do ângulo de incidência do feixe de ultra-som (fig. 6). Este fenômeno, conhecido como anisotropia, têm sido atribuído à orientação das fibras miocárdicas ${ }^{37,38}$. Assim sendo, segmentos paralelos ao feixe de ultra-som, como, por exemplo, os segmentos laterais nas projeções paraesternais de eixo curto, apresentam resposta inversa ao observado nos segmentos septais anteriores, ou seja, aumento da intensidade do integrated backscatter durante a contração ventricu$\operatorname{lar}^{10}$. A hipótese mais aceita para explicar esse fenômeno procura implicar mudanças no ângulo de incidência do ultra-som sobre o tecido estudado durante a contração ventricular.
A

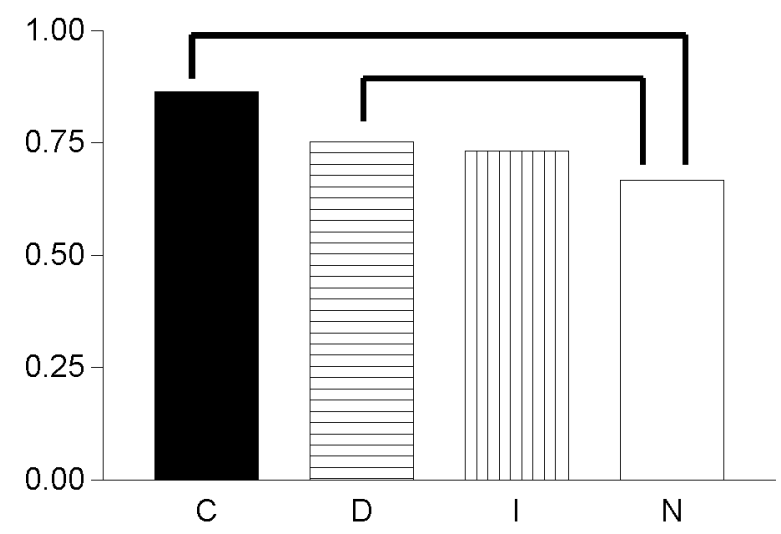

B

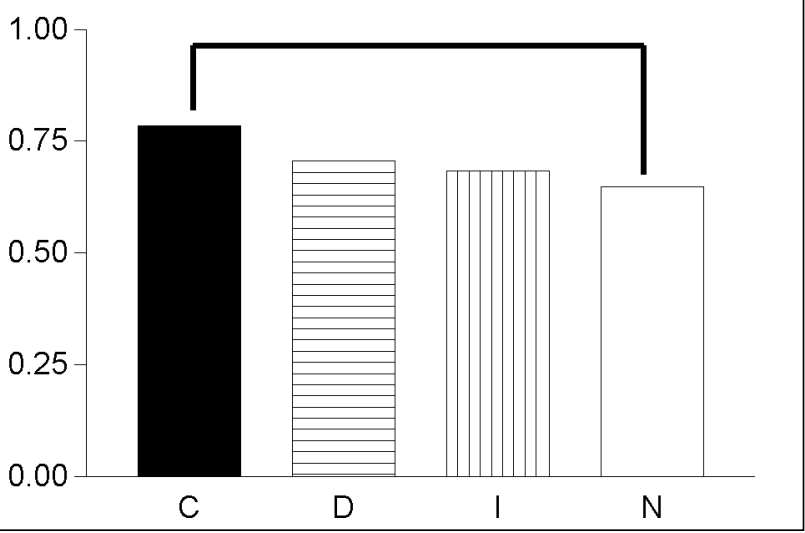

Fig. 5 - Os gráficos A e B apresentam dados de integrated backscatter obtidos em nosso laboratório para pacientes chagásicos (C-forma cardíaca; $\mathrm{D}$ - forma digestiva e I-forma indeterminada) comparados a dados obtidos em voluntários normais $(\mathrm{N})$ : A) índice do coeficiente corrigido de backscatter para os 12 segmentos analisados de acordo com a forma da doença e comparado ao grupo normal. Observou-se significância estatística $(\mathrm{p}<0,05)$ entre o grupo de chagásicos cardíacos e digestivos quando comparados aos voluntários normais (indicados pelas barras acima das colunas); B) exemplo do coeficiente corrigido de backscatter para um dos segmentos analisados seguindo a mesma notação expressa em A. Observe a significância estatística entre o grupo de chagásicos cardíacos quando comparado ao grupo de voluntários normais. 


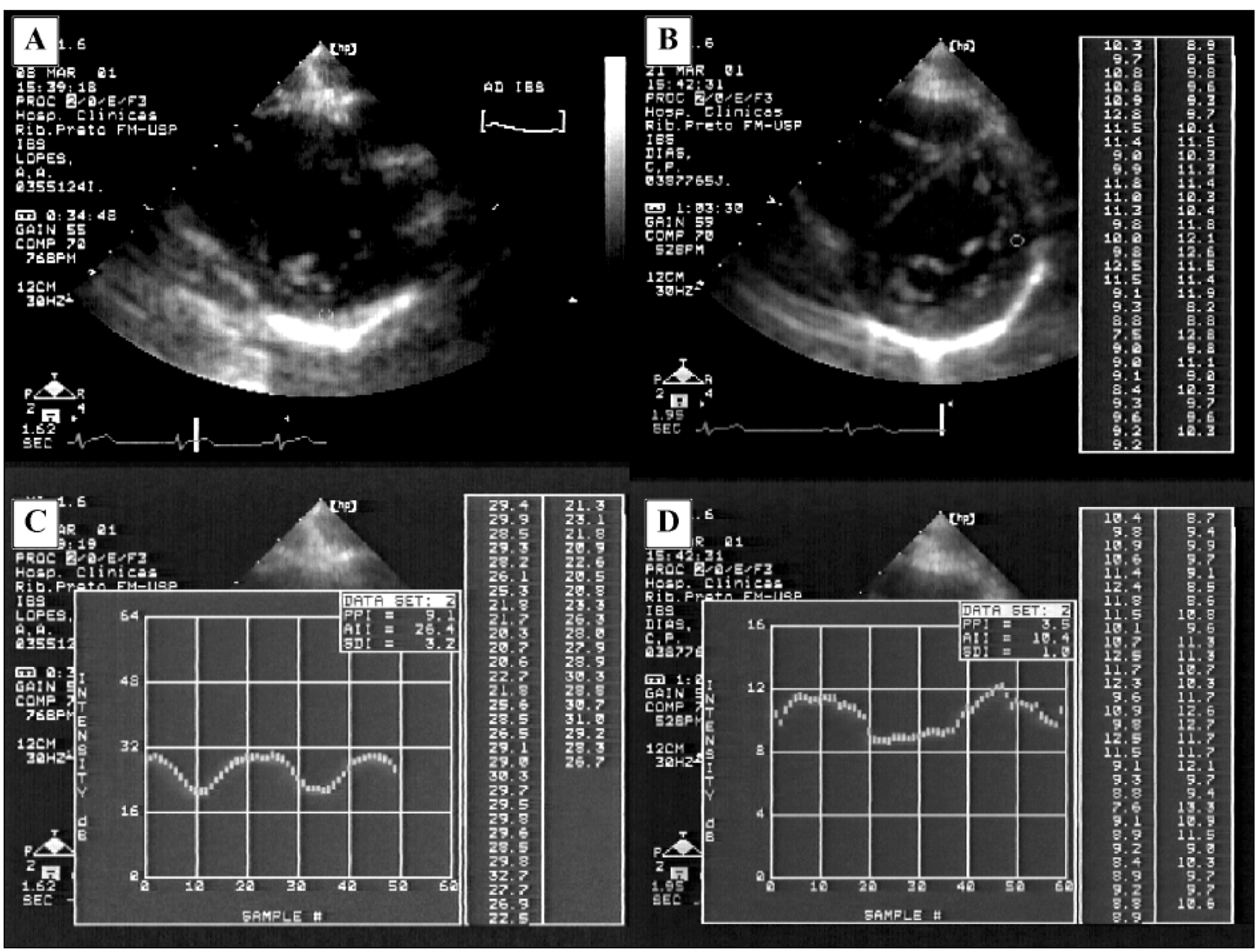

Fig. 6 - A e B) exemplos de uma projeção do ventrículo esquerdo no eixo curto ao nível da valva mitral com a região de interesse (RI) colocada no segmento inferior basal (A) e no segmento ântero-lateral basal (B); C) exemplo da curva produzida pela investigação do segmento mostrado em A, onde se observa nas ordenadas o valor do integrated backscatter e nas abscissas o número do quadro de 1 a 60 correspondente. Note que o valor do integrated backscatter diminui com a sístole ventricular. Este padrão de resposta é observado em segmentos perpendiculares à incidência do feixe de ultra-som; D) exemplo da curva produzida pela investigação do segmento mostrado em $\mathrm{B}$, onde se observa nas ordenadas o valor do integrated backscatter e nas abscissas o número do quadro de 1 a 60 correspondente. Note que o valor do integrated backscatter aumenta com a sístole ventricular. Este padrão de resposta é observado em segmentos paralelos à incidência do feixe de ultra-som.

Anormalidades estruturais do miocárdio são capazes de alterar esta propriedade. Assim sendo, em modelos de isquemia aguda ${ }^{39}$ e de rejeição aguda de transplante cardíaco $^{40}$, observaram-se alterações do padrão da curva de variação cíclica do integrated backscatter, tais como, inversão do padrão ou redução da amplitude e retardo da mudança de fase em relação ao início da contração ventricular. Essas alterações podem ser atribuídas a mudanças dinâmicas, como edema, ou a alterações crônicas, como as decorrentes de processo fibrótico, que impliquem em desestruturação da organização tridimensional do esqueleto de colágeno, dando sustentação ao miocárdio.

Estas observações implicam que um novo parâmetro deva ser levado em consideração, ao se analisar a caracterização tecidual através do integrated backscatter: a fase da curva, ou seja, se ela é síncrona (valores do integrated backscatter diminuem durante a contração ventricular) ou assíncrona (valores de integrated backscatter aumentam com a contração ventricular), ou ainda se apresenta um pa- drão incaracterístico (quando o padrão de variação cíclica não é bem definido). Este padrão de variação tem sido investigado na literatura por meio de várias metodologias. Alguns trabalhos procuraram estimar o efeito de fase de modo quantitativo, mediante a análise do retardo de tempo entre o nadir da curva e o início da sístole ventricular (timedelay), definido pelo pico do QRS no eletrocardiograma ${ }^{32}$ ou pela maior dimensão da cavidade ventricular ao longo do

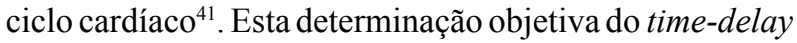
envolve tempo excessivamente longo, uma vez que depende de processamento off-line e não foi incorporada nos aparelhos comercialmente disponíveis. A abordagem desse problema pode ser realizada mediante análise qualitativa da curva, classificando o padrão como esperado ou não para aquele determinado segmento ${ }^{39}$, considerando-se a sincronicidade com a sístole ventricular.

Em síntese, a caracterização tecidual ultra-sônica, avaliada mediante a quantificação do integrated backscatter, constitui técnica não invasiva, demonstrando potencial para identificar alterações da refletividade tecidual ao ultra- 
som que podem ser correlacionadas com alterações morfológicas dependentes de diferentes tipos de doenças com envolvimento cardíaco. Assim, a caracterização tecidual poderá contribuir para a melhor compreensão dos mecanis- mos determinantes do envolvimento cardíaco nessas doenças, bem como oferecer elementos adicionais importantes para o aprimoramento do seu diagnóstico e das implicações prognósticas decorrentes.

\section{Referências}

1. Rasmussem S, Corya BC, Feigenbaum H, Knoebel SB. Detection of myocardium scar tissue by M-mode echocardiography. Circulation 1978; 57: 230-7.

2. Wilkins GT, Weyman AE, Abascalum VM, Palácios IF. Percutaneous balloon dilatation of the mitral valve: an analysis of echocardiographic variables related to outcome and the mechanism of dilatation. Br Heart J 1988; 60: 299-308.

3. Shiguerida-Filho SG, Cunha CLP, Tajik AJ: M-mode and two-dimensional echocardiography features in cardiac amyloidosis. Circulation 1981; 63:188-96.

4. Pearlman JD, Weyman AE. Tissue characterization. In: WeymanAE(ed.) Principles and Practice of Echocardiography. Philadelphia: Lea \& Febiger, p 1264-87, 1994.

5. Gibson D. Ultrasonic tissue characterization of myocardium. In: Sutton MSJ, Oldershaw PJ (ed.) Textbook of adult and pediatric echocardiographic and Doppler. Cambridge: Blackwell Scientific Publication, Inc., p 545-54, 1989.

6. Wickline SA, Sobel BE. Ultrasonic tissue characterization: prospects for clinical cardiology. JAm Coll Cardiol 1989; 14: 1709-11.

7. Rijsterborgh H, Mastik F, Lancée CT, Verdouw P, Roelandt J and Bom N. Ultrasound myocardial integrated backscatter signal processing: frequency domain versus time domain. Ultrasound Med Biol 1993; 19: 211-9.

8. Moran CM, Sutherland GR, Anderson T, Riemersma RA, McDicken WN.A comparison of methods used to calculate ultrasonic myocardial backscatter in the time domain. Ultrasound Med Biol 1994; 20: 534-50.

9. Schwarz KQ, Chen X, Steinmetz S. Methods for quantifying ultrasound backscatter and two-dimensional video intensity: implications for contrast-enhanced sonography. J Am Soc Echocardiogr 1998; 11: 155-68.

10. Lange A, Moran CM, Palka P, Fenn LN, Sutherland GR, McDicken WN. The variation of integrated backscatter in human hearts in differing ultrasonic transthoracic views. J Am Soc Echocardiogr 1995; 8: 830-38.

11. Naito J, Masuyama T, Tanouchi J, et al. Analysis of transmural trend of myocardial integrated ultrasound backscatter for differentiation of hypetrophic cardiomiopathy and ventricular hypertrophy due to hypertension. J Am Coll Cardiol 1994; $24:$ 517-24.

12. DiBello V, Talarico L, Picano E, et al. Increased echodensity of myocardial wall in the diabetic heart: an ultrasound tissue characterization study. J Am Coll Cardiol 1995; 25:1408-15.

13. Lattanzi F, SpiritoP, Picano E, etal. Quantitative assessment of ultrasonic myocardial reflectivity in hypertrophic cardiomyopathy. JAm Coll Cardiol 1991; 17:1085-90.

14. Lattanzi F, Di Bello V, Picano E, et al. Normal ultrasonic myocardial reflectivity in athletes with increased left ventricular mass: a tissue characterization study. Circulation 1992; 85: 1828-34.

15. Gigli G, Lattanzi F, Lucarini AR, et al. Normal ultrasonic myocardial reflectivity in hypertensive patients: a tissue characterization study. Hypertension 1993; 21:329-34.

16. Lucarini AR, Talarico L, Di Bello V, Paterni M, Pedrinelli R, Picano E. Increased myocardial ultrasonic reflectivity is associated with extreme hypertensive left ventricular hypertrophy: a tissue characterization study. Am J Hypertens 1998; 11: 1442-49.

17. Sagar KB, Agemura DH, O’Brien Júnior WD, et al. Quantitative ultrasonic assessment of normal and ischaemic myocardium with an acoustic microscope: relationship to integrated backscatter. Cardiovasc Res 1990; 24: 447-55.

18. Davison G, Hall CS, Miller JG, Scott M, Wickline AS. Ultrasonic tissue characterization of end-stage dilated cardiomyopathy. Ultrasound Med Biol 1995; 21: 853-60.

19. Rose JH, Kaufmann MR, Wickline SA, Hall CS, Miller JG. A proposed microscopic elastic wave theory for ultrasonic backscatter from myocardial tissue. J Acousti Soc Am 1995; 97: 656-68.

20. Mottley JG, Miller JG. Anisotropy of the ultrasonic backscatter of myocardial tissue: I. Theory and measurements in vitro. J Acoust Soc Am 1988; 83: 755-61.

21. Hall CS, Scott MJ, Lanza GM. The extracellular matrix is an important source of ultrasound backscatter from myocardium. J Acoust Soc Am 2000; 107: 612-9.

22. Naito J, Masuyama T, Mano T, et al. Ultrasonic myocardial characterization in patients with dilated cardiomyopathy: value in noninvasive assessment of myocardial fibrosis. Am Heart J 1996; 131:115-21.
23. Lucarini AR, Gigli G, Lattanzi F, et al. Regression of hypertensive myocardial hypertrophy does not affect ultrasonic myocardial reflectivity: a tissue characterization study. J Hypert 1994; 12: 73-9.

24. Lattanzi F, Bellotti P, Picano E, et al. Quantitative ultrasonic analysis of myocardium in patients with thalassemia major and iron overload. Circulation 1993 97: 748-54.

25. Mimbs JW, O'Donnell M, Miller JG, Sobel BE. Detection of cardiomyopathic changes induced by doxorubicin based on quantitative analysis of ultrasonic backscatter. Am J Cardiol 1981; 47: 1056-60.

26. Vanderberg BF, Rath L, Shoup TA, Kerber RE, Collins SM, Skorton DJ. Cyclic variation of ultrasound backscatter in normal myocardium is view dependent: clinical studies with a real-time backscatter imaging system. J Am Soc Echocardiogr 1989; 2: 308-14.

27. Madaras EI, Barzilai B, Perez JE, Sobel BE, Miller JG. Changes in myocardial backscatter throughout the cardiac cycle. Ultrason Imaging 1983; 5: 229-39.

28. Sagar KB, Pelc LE, Rhyne TL, Wann S, Waltier DC. Influence of heart rate, preload, aftertload, and inotropic state on myocardial ultrasonic backscatter. Circulation 1988; 77: 478-83.

29. Naito J,Masuyama T, Mano T, etal. Influence of preload, afterload, and contractility on myocardial ultrasonic tissue characterization with integrated backscatter. Ultrasound Med Biol 1996; 22: 305-12.

30. Gluek RM, Mottley JG, Miller JG, Sobel BE, Pérez JE. Effects of coronary artery occlusion and reperfusion on cardiac cycle-dependent variation of myocardial ultrasonic backscatter. Circ Res 1985; 56: 683-9.

31. Takiuchi S, Ito H, Iwakura $\mathrm{K}$, et al. Ultrasonic tissue characterization predicts myocardial viability in early stage of reperfused acute myocardial infarction. Circulation 1998; 97:356-62.

32. Pasquet A, D'Hondt AM, Melin JA, Vanoverschelde JLJ. Relation of ultrasonic tissue characterization with integrated backscatter to contractile reserve in chronic left ventricular ischemic dysfunction. Am J Cardiol 1998; 81:68-74.

33. Wu CC, Liu YB, Lin LC, Ho YL, Liau CS, Lee YT. Ultrasonic tissue characterization with integrated backscatter during inotropic stimulation. Ultrasound Med Biol 2000; 26:1413-20.

34. Bouki KP, Lange A, Palka P, et al. Regional variations of ultrasonic integrated backscatter in normal and myopathic left ventricles: a new multi-view approach. Eur Heart J 1996; 17:1747-55.

35. Masuyama T, St. Goar FG, Tye TL, Oppenheim G, Schnittger I, Popp RL. Ultrasonic tissue characterization of human hypertrophied hearts in vivo with cardiac cycledependent variation in integrated backscatter. Circulation 1989; 80:925-94.

36. Naito J, Masuyama T, Mano T, et al. Dobutamine stress ultrasonic myocardial tissue characterization in patients with dilated cardiomyopathy. J Am Soc Echocardiogr 1996; 9:470-9

37. Hoffmeister BK, WongAK, Verdonk ED, Wickline SA, Miller JG. Comparison of the anisotropy of apparent integrated ultrasonic backscatter from fixed human tendon and fixed human myocardium. J Acoust Soc Am 1995; 97:1307-13.

38. Holland MR, Wilkenshoff UM, Finch-Johnston AE, Handley SM, Perez JE, Miler JG. Effects of myocardial fiber orientation in echocardiography: quantitative measurements and computer simulation of the regional dependence of backscattered ultrasound in the paraesternal short-axis view. JAm Soc Echocardiogr 1998; 11:929-37.

39. Castaldo M, Funaro S, Veneroso G, Agati L. Detection of residual tissue viability within the infarct zone in patients with acute myocardial infarction: ultrasonic integrated backscatter analysis versus dobutamine stress echocardiography. J Am Soc Echocardiogr 2000; 13:358-67.

40. Masuyama T, Valantine HA, Gibbons R, Schnittger I, Popp RL. Serial measurement of integrated backscatter in human cardiac allografts for the recognition of acute rejection. Circulation 1990; 81:829-39.

41. Finch-Johnston AE, Gussak HM, Mobley J, et al. Dependence of "apparent" magnitude on the time delay of cyclic variation of myocardial backscatter. Ultrasound in Med \& Biol 1999; 25:759-62. 